\title{
Relações Sociais e Sentidos de Justiça Social após a Adoção da Política de Cotas na U niversidade Federal de Sergipe
}

Yérsia Souza de Assis ${ }^{1}$

Neste texto investigo as relações de distinção que são constituídas entre os alunos cotistas e não cotistas nos cursos de Medicina e Direito da Universidade Federal de Sergipe. Busco também entender como são ativadas as percepções que os estudantes têm sobre justiça social, meritocracia e desigualdade social, vinculadas ao debate sobre as ações afirmativas e as cotas para ingresso na universidade pública nos cursos de graduação. Além dessas percepções, analiso quais sentidos são acionadas por eles quando o assunto é cotas raciais. Este artigo é oriundo da pesquisa que desenvolvi no Mestrado através do Núcleo de Pesquisa e Pós - Graduação em Antropologia da Universidade Federal de Sergipe, sendo este artigo, um desmembramento de um capítulo de minha Dissertação defendida recentemente. Fundamentalmente, quis compreender como são instituídas as diferenças entre os estudantes através do impacto das cotas no contexto universitário. Ou seja, saber se o quesito "cotas" conta como determinante na produção das diferenças dentro das relações estabelecidas pelos estudantes dos dois cursos.

Palavras-Chave: Ações Afirmativas; Cotas; Justiça Social; Justiça Racial

\footnotetext{
${ }^{1}$ Yérsia Souza de Assis. Cientista Social/UFS. Mestre em Antropologia, pela UFS. Membro do GERTS/UFS - Grupo de Estudos Culturais, Identidades e Relações Interétnicas; Membro do NEAB/UFS. Estuda Ações Afirmativas; Cotas no Ensino Superior; Racismo. Contato: yersiasouza@gmail.com
} 


\section{Social Relations and Sense of Social Justi- ce after the adoption of the Q uota Policy at the Federal U niversity of Sergipe}

Abstract

In this article I focus on the relationships that are established of difference between the quota and non-quota students of Medicine and Law at the Federal University of Sergipe. I also seek to understand how perceptions that students have about social justice, meritocracy and social inequality are activated, which are linked to the debate over affirmative action and quotas for entry into undergraduate courses at public universities in. In addition to those perceptions, I analyze what senses are triggered by the students when it comes to racial quotas. This article derives from the research I conducted for a Master's degree from the Center for Research and Post - Graduate Anthropology at the Federal University of Sergipe, this article, is a version of a chapter of my recently defended thesis. Essentially, I seek to understand how differences are established among students through the impact of quotas in the academic context. In other words, I inquire whether the item "quota" is decisive in the production of the differences in the relationships among students of the two majors. Keywords: affirmative action; quotas; social justice; racial justice

\section{Introdução}

Neste artigo enfatizo as relações de diferença que são estabelecidas entre os alunos cotistas e não cotistas nos cursos de Medicina e Direito da Universidade Federal de Sergipe. Busco também entender como são acionadas as percepções que os estudantes têm sobre justiça social, meritocracia e desigualdade 
social, vinculadas ao debate sobre as ações afirmativas e as cotas para ingresso na universidade pública. Além dessas percepções, analiso quais relações de sentido são acionadas por eles quando o assunto é cotas raciais.

Este artigo é oriundo de um capítulo de minha Dissertação de Mestrado defendida recentemente sobre o assunto. Durante a pesquisa, realizei observação participante, questionários e entrevistas junto aos alunos e professores dos dois cursos em questão, procurando perceber como são ativadas as diferenças de identificação entre os estudantes cotistas e não cotistas, ao mesmo tempo em que frequentei as aulas e procurei socializar-me no dia a dia com alunos.

Basicamente, quis entender como são constituídas as diferenças entre os estudantes através do impacto das cotas no contexto acadêmico. Ou seja, saber se o quesito "cotas" conta como condicionante da produção das diferenças dentro das relações estabelecidas pelos estudantes dos dois cursos. Deste modo, tratei de analisar se esses grupos carregam alguns demarcadores que os diferencia dentro do debate sobre as cotas na UFS. Para isto, é preciso dizer que os dois cursos foram, durante décadas, os mais concorridos nos vestibulares da universidade e formas profissionais de duas áreas de grande prestígio social. Até a adoção do sistema de cotas para ingresso nos mesmos, no ano de 2010, menos de $10 \%$ dos alunos que ingressavam pelo vestibular eram oriundos de escolas públicas. Após a adoção do programa, reservou-se 50\% das vagas para alunos de escola pública e 70\% destas vagas para autodeclarados negros, pardos e indígenas.

A partir de tal quadro e de uma nova composição social nos cursos de Medicina e Direito, desde então, prossigo a discussão propondo reuni as percepções de justiça social, meritocracia e desigualdade social que tais estudantes elaboram e suas perspectivas sobre as cotas sociais. Faço essa discussão marcando a política de cotas, na modalidade cota social, como um instrumento que 
pode ou não combater as desigualdades e fomentar a justiça social. Compreendo que para esses alunos o sistema de reserva de vagas é acionado junto ao repertório de medidas associadas a essas percepções. Posteriormente, analiso aqui as percepções que os alunos têm das cotas raciais, traçando um paralelo ao sentido empregado por eles sobre as cotas raciais e as discussões sobre raça, racismo e desigualdade racial. Objetivamente, quero entender como os alunos pensam as cotas raciais e se eles acionam os mesmos argumentos que legitimam as cotas sociais no sentido de combate as desigualdades e ao fomento da justiça social. Também faço uso das entrevistas como aporte para tais reflexões

Por fim, busco compreender como se estabelecem as diferenças entre cotistas e não cotistas, além de evidenciar os usos que os alunos fazem para legitimar as cotas por meio das suas percepções sobre justiça, desigualdade e mérito. Meu objetivo é também refletir sobre como a perspectiva das cotas é acionada pelos estudantes. Assim como, quais argumentos eles utilizam para entender as cotas raciais numa esfera legítima ou não de combate as desigualdades e fomento de justiça.

\section{D istinção: M ecanismos de diferença entre cotistas e não cotistas}

As universidades públicas federais, por autonomia ou por força de lei, atualmente tiveram de implantar o sistema de reserva de vagas. Em geral, as experiências sobre as cotas estão associadas a significados não muito positivos. Pensando sobre o programa de ações afirmativas da UFS, observei os relatos dos alunos na perspectiva de apontar as distinções que fazem parte do universo acadêmico de cotistas e não cotistas.

Interroguei os alunos sobre o que entendiam por diferenciação e como eles detectavam uma situação onde havia distinção entre não cotistas e cotistas. A resposta mais comum entre os professores e 
os alunos entrevistados é que para eles, "não há diferenciação". No entanto, aprofundando a conversa e mudando a pergunta ouvi vários relatos onde mecanismos de diferenciação foram acionados na relação cotidiano dos alunos entre si e com os professores.

Tanto alunos como professores procuravam justificar que mesmo com alguns problemas, a realidade dos cursos era de uma vivência harmoniosa, sem grandes contratempos. Relataram que os alunos conviviam bem entre si, mesmo aqueles que se posicionavam contra as cotas. Tensionamentos públicos não haviam acontecido, no sentido material e formal, ou quase nunca aconteceram, segundo eles. Contudo, não significa dizer que não existam.

As distinções foram notadas pelos alunos e relatadas para mim depois de muito diálogo. Na maioria das vezes o aluno entendia que os mecanismos de exclusão estão associados a elementos que não podem ser dissociados das pessoas, como sua classe social ou origem escolar. Estudantes e professores acreditam que o demarcador das cotas não se torna um agravante na distinção, mas sim outros elementos que acompanham o sujeito e que de forma ou de outra podem ser assimilados pelo grupo dos cotistas ou dos não cotistas,

$4 D^{2}$ : Assim... Quando eu cheguei eu pensei que pesaria um pouco mais, né? A gente é... Percebe... Acreditava que quando chegasse podia sofrer algum tipo de rejeição. Assim, é quando cheguei aqui eu notei que não há uma rejeição,

\footnotetext{
${ }^{2}$ Decidi que para expor os dados seria interessante utilizar os números de entrevistas combinados com as iniciais dos cursos (Direito e Medicina), formando, assim, um código alfanumérico que identifica e diferencia os entrevistados, bem como lhes garante a total preservação da identidade. A fim de ilustrar o que digo, cito "1D", um dos entrevistados. Ele foi a minha primeira entrevistada no campo do curso de Direito, isto é, "1D": Primeira entrevista no Direito. "1M": Primeira entrevista na Medicina. A ordem segue o número de entrevistas. Por vezes, em um mesmo parágrafo cito duas entrevistas que serão diferenciadas pelo número e pela inicial do curso. Essa foi a maneira encontrada para não comprometer a identidade dos sujeitos entrevistados, expressando algumas de suas características importantes como o curso e o acompanhamento de suas falas. "4D" foi o quarto aluno entrevistado no curso de Direito.
} 
algum tipo de segregação, alguma coisa do tipo. É mais a questão de você é... Ter afinidade ou não com determinado grupo. Eu acho que a gente vem de uma classe social um pouco inferior, a gente tem um comportamento diferenciado, uma forma de se portar diferente. Então, isso acaba dificultando a relação, mas eu não acredito que isso seja uma coisa assim... Fruto de uma ação que o pessoal desenvolva contra a gente. Até porque, a gente nota que alguns colegas demonstram em alguns momentos, nos debates, algumas posições contrárias. Mas, que a gente tem o espaço de poder expor nosso pensamento e eu acho que isso não interfere muito.

Alguns alunos acreditam que as diferenças que existem entre eles e os seus colegas não cotistas devem ser atribuída à classe social da qual são oriundos, o que não deixa de ser um fato. Uma vez que, este mecanismo de distinção foi eleito tanto pelo grupo dos não cotistas como dos cotistas como instrumento nas relações de afinidade. Nestes cursos, esse é um fator que pesa notadamente, uma vez que, são graduações que historicamente recebiam um tipo de perfil social e econômico.

Os alunos de forma geral conseguem elencar os pontos que os fazem ser diferentes entre si: poder aquisitivo, origem escolar, espaços de sociabilidade. As demarcações simbólicas e materiais existem e exercem influência real nas relações dos estudantes. Diferente do que a opinião pública acreditou que aconteceria, as diferenças entre os grupos acontece numa esfera sutil e pormenorizada. Com isso não quero dizer que ela não seja perversa ou que não deixe sequelas.

Os alunos não cotistas tendem a minimizar os fatos que sejam associados às distinções, sobretudo, porque as situações em que há distinção com conotação de exclusão geralmente ocorrem de não cotista para cotista. Entendi essa postura do aluno não cotista, como um recurso estratégico utilizado por esses alunos na perspectiva de não serem considerados preconceituosos ou mesmo racistas. Entretanto, essa não é a versão dos alunos co- 
tistas que acreditam serem protagonistas de situações onde há e houve preconceito e até mesmo racismo,

3D: Chega a ser hostil... Quando você fala com a pessoa e ela vira a cara literalmente. Ah, às vezes você se sente desconfortável, porque você vem para a universidade e pensa: vou estudar e você com um chinelinho, uma coisa. Aí você vê as meninas, entram todas com roupas, aí você para e se sente deslocado. Se você não tiver uma maturidade, assim, de pensar o porquê... 0 estudante realmente se sente deslocado, como tem gente, assim, que tenta se equiparar a eles [não cotistas]. E como tem estudante que percebe isso, e se fecha totalmente em si, aí nem conversa com eles [não cotistas]. 0 engraçado é que quando têm essas pessoas, eles [não cotistas] sempre dizem que esse grupo é fechado em si. (...) Assim... Não chega para dizer você é negro, você é... Porque isso é feio. Mas, demonstra de outras formas.

Neste ponto, alunos cotistas e não cotistas começam a divergir em seus relatos, enquanto alunos cotistas acreditam que sofrem situações de preconceito e exclusão, os alunos não cotistas acreditam em um contexto de convivência harmoniosa, sem maiores dificuldades. O lugar que os alunos não cotistas ocupam em seus cursos e até na universidade como um todo possibilita que eles acreditem que não há distinção.

Utilizando-se de mecanismos que aparentemente podem ser interpretados como atos não discriminatórios, os alunos estabelecem estratégias de diferenciação. Segundo alguns alunos, o que acontece é que muitos colegas não verbalizam os formatos de distinção, porém os reproduzem nas atitudes, assim como explica o aluno 5D "Não falavam mal, mas tratavam mal".

Entendo a distinção como um aspecto negativo no condicionante que forma a experiência universitária dos alunos cotistas, em especial, porque também é um momento na trajetória do individuo marcado por novas fases e desafios. Neste sentido, estou analisando a distinção como mecanismo utilizado para excluir 
e segregar os alunos cotistas de forma geral e em especial nos cursos de Direito e Medicina. A distinção como experiência negativa, pela qual passam os alunos cotistas exerce forte efeito nas redes sociais e acadêmicas que são construídas ao longo da trajetória acadêmica.

Os mecanismos de diferenciação não ficam restritos ao universo das relações constituídas pelos alunos. Para os professores, o sistema de cotas impactou também os formatos de suas aulas e de sua relação com o alunado. Essa alteração acontece, especialmente, porque o grupo que ingressa deixa de ser em sua totalidade de pessoas com as quais alguns dos professores já mantinham algum tipo de contato e vínculo. Essa situação fez também com que fossem criados determinados mecanismos de diferenciação dos professores para com os alunos cotistas e não cotistas, sobretudo, com os cotistas como grupo que causa maior estranhamento.

A forma com a qual os professores resolveram lidar com a situação passa por um posicionamento em que a neutralidade é o argumento principal, com a expectativa de não se envolver em situações embaraçosas. Os professores do Departamento de Direito, por exemplo, preferiram posicionar suas opiniões sobre alunos cotistas numa esfera de desconhecimento, isto é, eles afirmam não saber quem são os alunos cotistas ou não cotistas. Em contrapartida, professores do curso de Medicina verbalizam mais intensamente suas opiniões contrarias sobre as cotas, obviamente esses professores não nomeiam ninguém, todavia, afirmam também não saber quem são objetivamente os estudantes.

Não identificar os estudantes, pode ser interpretado como um ato de resistência ao debate e também de resistência à presença desses estudantes. É perceptível que os docentes encaminham a relação deles com os alunos cotistas para uma esfera de total distanciamento. Sendo esta, uma posição que os protege de qualquer impasse oriundo desse novo momento da universida- 
de. Entendi esse tipo relação como um mecanismo que invisibiliza as discussões sobre as cotas, como invisibiliza os próprios estudantes.

As posturas neutras empregadas pelos professores veem também na perspectiva de tornar a prática docente isenta de traços de discriminação e preconceito. Dessa forma, eles se excluem de qualquer situação que os coloque numa posição vexativa. Essa posição neutra precisa ser encarada no seu aspecto prejudicial ao debate sobre inserção de novos grupos sociais, econômicos e raciais na universidade, bem como à reflexão sobre a democratização do ensino superior.

Afirmar que não distinguem um aluno do outro, não implica inexistência de preconceito ou discriminação. As atitudes, na maioria das vezes, acontecem de maneira tão subjetiva, assim como o racismo no Brasil, que é bastante difícil dimensionar como ato discriminatório. Essas situações ocorrem no cotidiano da universidade e dificilmente são interpretadas como formas de discriminação para com os alunos cotistas. Assim como, o fato de não se querer distinguir alunos com a justificativa de não discriminar, cria formas peculiares de resistência à inserção desses grupos.

De alguma forma, o posicionamento dos professores também demonstra a dificuldade simbólica e formal de aceitar as cotas. Assim como os docentes, alguns outros setores da universidade ainda resistem em aceitar a política de cotas "demonstra-se a dificuldade da instituição em adaptar-se ao sistema de cotas, sendo sua ação mais no sentido de que os cotistas adaptem-se à Universidade. (...)" (SILVEIRA et al, 2013, p.174).

Entendo que a resistência em aceitar as cotas se dê no plano social e simbólico, sobretudo no acadêmico, a partir das relações fomentadas em sala de aula e nos espaços de convívio. Essas formas de resistências revelam a negação e o não prestígio com qual é enxergado o aluno cotista. Quando isso acontece, os alunos 
e professores que preliminarmente se posicionaram como neutros na enunciação e nos atos para com alunos cotistas revelam as suas resistências e inconformidades com as cotas e com os alunos cotistas. Reforçando isso, os alunos cotistas acreditam em formas de distinção aplicadas pelos seus colegas e professores.

Outro arranjo distintivo da relação dos estudantes é a forma como eles se posicionam enquanto grupo de cotista e não cotista. Isto acontece dentro de uma perspectiva polarizada, onde no polo passivo estariam os alunos cotistas e no polo ativo estariam os alunos não cotistas. Notei essa polarização a partir dos relatos dos estudantes, a partir dos quais as enunciações dos alunos giram em torno da construção social e simbólica que a categoria cotista e não cotista carrega. Para eles, o sentido associado às cotas é de pobreza, desigualdade, origem escolar deficiente e até mesmo ocupação de um espaço não legítimo. 0 sentido associado aos não cotistas é de capacidade intelectual, recursos financeiros e, principalmente, uma herança educacional e familiar de formação e atuação dos pais na área dos cursos.

Esses aspectos forjam concepções sobre o tipo de aluno adequado para os referidos cursos, fazendo com que os estudantes cotistas sejam encarados como "pseudo alunos". Funcionando também na relação de distinção pela qual passam diariamente. Esta situação é encarada pelos alunos cotistas como um dos principais demarcadores do estigma de ser cotista,

3D: Para o estudante de direito eu acho que há uma certa vergonha de dizer eu sou cotista e se debater isso em sala de aula. 0 professor pergunta quem é de colégio particular levanta a mão; quem é de colégio público? Aí fica todo mundo assim... Meio tímido... Num sei por quê. Pode demonstrar uma incapacidade ou uma fraqueza, num é? Acho que as pessoas se incomodam porque já tem uma segregação assim visível, na prática. Na verdade assim, as pessoas se incomodam de... Para se resguardar mais. Tipo... É melhor 
não parecer que sou cotista e imitar certos padrões de não cotista, né?

Os alunos cotistas entendem sua condição de cotistas, e de que ser cotista é muito mais do que utilizar um recurso educacional para ingressar na universidade. Existe para alunos cotistas e não cotistas um repertório de atos, atitudes e comportamentos diários que dizem quem eles são para os seus colegas, professores e para universidade. De modo que para os alunos cotistas, esse repertório tem sido utilizado como ferramenta empregada para distinguir esses alunos na dimensão de categorizá-los. Como diria Goffman "a sociedade estabelece meios de categorizar as pessoas e o total de atributos considerados como comuns e naturais para os membros de cada uma dessas categorias." (GOFFMAN, 1978, p. 11).

No caso dos alunos cotistas, as categorias que os acompanham, com frequência, os inferiorizam. Muitos dos relatos feitos pelos estudantes cotistas demonstram que na relação de distinção que ocorre no cotidiano acadêmico eles são surpreendidos por situações onde os seus colegas e até seus professores relevam como os enxergam,

\begin{abstract}
3D: Um professor, ele fez um debate na sala de aula que era um júri simulado. Botou alunos que eram a favor das cotas e alunos que eram contra as cotas no júri para decidir. Nesse debate, você tinha argumentos porque você ser contra ou a favor das cotas e eu me levantei e falei. Até então, as pessoas não sabiam que eu era cotista, pensavam que eu não era cotista e uma determinada colega [não cotista] de curso chegou para mim surpresa e falou: 3D, você é cotista? Eu disse: sou cotista. Na mesma hora era a fala dela, e ela levantou e falou: olhe, ta [sic] vendo 3D é inteligente e é cotista... [pausa, ele me olhou fixamente] (...).
\end{abstract}

Uso este relato com a finalidade de demonstrar quais as categorias que os alunos cotistas são associados e de como eles, enquanto alunos cotistas compreendem que são considerados como menos capazes. Não sei qual será o efeito reiterado dessas situações cotidianas na trajetória acadêmica dos estudantes 
cotistas, o que posso confirmar é que as categorias que acompanham os alunos cotistas tendem a ser mais negativadas, sobretudo, no aspecto intelectual destes alunos.

Na esfera intelectual, os alunos cotistas também são diferenciados dos seus colegas pelo domínio da língua estrangeira, tão útil no ensino superior. Os alunos afirmam que este também é um recurso utilizado para diferenciar quem entrou pelas cotas e quem não, refletindo em mais uma barreira nas relações. Este fato também atinge a vida universitária do aluno cotista, pois, em alguns momentos é exigido dele o domínio de uma segunda língua,

3M: Na minha sala... Essa questão de linguagem, você vê nítido a galera que entrou por cota: a galera fala português [risos]. Tipo, não tem uma segunda língua. A outra galera não, fala inglês, francês, espanhol. Aí se vê na... Ah, tipo, sei lá... Festinha, pá... A galera começa a beber, daí a pouco tem uma galera conversando em francês. Tipo, a galera que não sabe [risos]... Aí é bem diferente. (...)

O aluno satiriza o fato da segunda língua, porém, ele também compreende que se trata de um demarcado formal e simbólico entre cotistas e não cotistas. Além disso, o fato dos estudantes não cotistas dominarem outra língua os torna ainda mais autênticos enquanto estudantes universitários. Numa seleção interna com exigência de domínio de segunda língua, por exemplo, os alunos não cotistas em sua maioria são considerados mais aptos. Não quero dizer assim, que entre os alunos cotistas não existam os que dominem uma segunda língua ou que entre os alunos não cotistas todos dominem uma segunda língua. Quero chamar atenção para os demarcadores que são criados como instrumentos de diferenciação entre os grupos, independente de como individualmente cada aluno encare. 
Estou me referindo às categorias generalizadas criadas para nomear os alunos cotistas e não cotistas. Essas categorias foram construídas por esses alunos, professores e pela comunidade acadêmica antes da efetiva implementação das cotas e estão sendo reafirmadas ou resignificadas durante as relações que estão sendo constituídas com as cotas no cotidiano acadêmico,

3D : A questão de você ser taxado, lembrado como cotista...

É... Como se dissesse: você não é digno de estar aqui. Tipo, você não fez a pontuação correta, você não está aqui por meio da meritocracia, você esta aqui por meio do sistema social, porque você tem, é negro, pobre; e o governo resolveu dá, aplicar ações afirmativas para poder... É... Colocar na universidade e mascarar a educação pública. (...) Basicamente é isso, por isso que quando você ouve os comentários você é inteligente, mas é cotista, o entendimento que eu faço é: ele é inteligente, mas não vai chegar a ser o profissional que o não cotista vai ser, e vai de relacionamento, amizades... De amoroso! (...)

Os alunos cotistas em muitos momentos são lembrados da sua condição subalterna, seja ela na esfera econômica, social, intelectual ou de redes de afinidade. Esses elementos são acionados numa perspectiva de deslegitimar o lugar ocupado pelo estudante cotista, e estes seriam os efeitos quase invisíveis do impacto da política de cotas na universidade. Especialmente, porque no campo quantitativo os alunos cotistas têm o seu desempenho acadêmico igual ou superior do aluno não cotista: estou falando das notas, dos índices de abandono e reprovação. Em todo caso, a nota não se tornou um elemento que atenue as outras fronteiras simbólicas e sociais que permeiam o cotidiano dos alunos cotistas e não cotistas na UFS. Mesmo com notas semelhantes, os estudantes cotistas continuam sendo percebidos como ilegítimos.

Entendi que para os alunos não cotistas a resistência e os mecanismos de diferenciação se travestem também como uma forma de não saber lidar com uma nova situação e com pessoas com 
as quais não há uma unidade comum, a não ser o fato de serem alunos do mesmo curso. Para eles, a construção de uma relação com seus colegas cotistas é um processo meticuloso, pois, para muitos deles, existe um receio no modo de abordar estes colegas.

Esses mecanismos de diferenciação seriam os componentes de uma segunda avaliação sobre a política de cotas, nos seus aspectos poucos visíveis, mas que atingem a vida acadêmica do estudante. Como Neves (2013), entendo que observar como estão sendo estabelecidas as relações diárias dos alunos ajuda a compreender quais os posicionamentos esses grupos têm de outras questões ligadas às cotas e a própria vida social universitária.

Demonstrei como esses grupos tem mutuamente se visto durante o processo cotidiano de ser ou não cotista e de como esses ingredientes demonstram os mecanismos de estigma, preconceito e discriminação que as pessoas podem criar para manifestar o seu descontentamento ou inconformidade com uma situação. Neste caso, estou falando de grupos de alunos inseridos nas graduações de Medicina e Direito da única universidade pública federal de Sergipe após o sistema de reserva de vagas.

Nas narrativas colhidas, entendi que os posicionamentos apreendidos possibilitam refletir em que tipo de dimensão social e simbólica as cotas se encontram nos referidos cursos. Esses relatos indicaram qual é o efeito subjetivo das cotas, essas percepções possibilitaram que eu entendesse que o cotidiano acadêmico se alterou, ganhando novas fronteiras sociais e simbólicas. Se antes das cotas as turmas estabeleciam grupos a partir de outros demarcadores, agora eles acontecem através das cotas.

Por fim, depois entender que os grupos estabelecem e estabeleceram mecanismos de diferença entre si, quis entender como eles avaliam a política de cotas enquanto uma medida pública. Preliminarmente, as reflexões que fiz, respondem que para esses grupos a política de cotas seria um equívoco. Inclusive, pelos 
relatos que analisei, a primeira impressão é que esses alunos, especialmente os não cotistas, repugnam o sistema de reserva de vagas na em sua totalidade. No entanto, durante a pesquisa, tanto alunos quanto professores emitiram diversas opiniões sobre a política de cotas, principalmente, associados aos sentidos de justiça social, desigualdade, meritocracia.

As justificativas sobre o caráter justo e não justo das cotas se pautam também nos entendimentos que são feitos sobre o fracasso da escola pública, da desigualdade e exclusão social, bem como nos privilégios dos alunos da rede privada versus rede pública. Deste modo, apresento a seguir os elementos da narrativa desses sobre as cotas sociais como uma medida importante ao acesso a cursos de graduação e na terceira parte o entendimento que fazem sobre as cotas raciais.

\section{Justiça Social ou Como as Cotas Sociais são aceitas}

Os alunos dos cursos de Direito e Medicina acionam os sentidos de igualdade, justiça e desigualdade quando emitem sua opinião sobre as cotas enquanto recurso público. Atentei-me também para as opiniões feitas sobre a escola pública e para o seu fracasso enquanto instrumento que possibilite o acesso de estudantes ao ensino superior público. Pretendo entender como os alunos fazem associações com as cotas quando eles acionam os termos de justiça, igualdade e desigualdade. A ideia é entender quais argumentos são utilizados para legitimar ou não as cotas enquanto justas ou não.

Há de se ponderar para como o debate público se encaminhou para oscilação de considerar a implantação do sistema de reserva de vagas nos cursos de graduação como uma medida justa ou injusta, como afirmam Neves e Lima (2010). Neste caso, a validade da adoção das políticas de ações afirmativas é também apreendida como um recurso que promove o combate sobre as 
desigualdades sociais por um lado, e por outro lado é visto como instrumento que questiona o sentido da meritocracia. “É na arena de debates sobre justiça e igualdade social que se inserem as discussões sobre as políticas de ação(s) afirmativa(s) para grupos minoritários" (NEVES E LIMA, 2010, p.68).

A discussão sobre cotas além de alavancar os debates sobre justiça e igualdade, trouxe para o centro da discussão também os entendimentos que são feitos sobre quais as formas de reconhecimento e reparação que estão sendo construídas pelo Estado para os grupos que as reivindicam, como os movimentos sociais negros e LGBT. Como diria Walzer, "os significados sociais são históricos em caráter. Portanto, as distribuições justas e injustas, mudam com o tempo" (WALZER, 2003, p. 9.).

Diante disso, vale observar que as ações do Estado na busca por reparar assimetrias a determinados grupos mudaram com tempo, atualmente tendo por finalidade o argumento da promoção da justiça social. Essa justiça social como afirma Fraser (2002) abrange não só medidas distributivas, mas questões ligadas à representação, identidade e diferença. Deste modo, pensar sobre as politicas públicas no Brasil, sobretudo a política de Ações Afirmativas, em especial as cotas no ensino superior brasileiro, é observar quais são os imperativos condicionantes que permitem a implantação desta medida como um instrumento que promova a justiça social para as pessoas e o sentido dado por elas a ideia de justiça social.

Entendendo este cenário, interroguei alunos e professores sobre o caráter justo das cotas, busquei entender quais seriam os elementos reunidos por eles para justificar ou não a política de cotas como uma medida pública justa e assertiva. Supreendentemente, os alunos, em sua maioria, consideram justas as cotas, o que demonstra dois tipos de posturas diante do universo das cotas, uma ligada aos aspectos do cotidiano e das relações estabelecidas entre os grupos de cotistas e não cotistas, e outro 
relacionado às opiniões formais que os estudantes têm sobre as cotas, especialmente, quando analisadas na perspectiva de uma medida pública.

Alunos e professores acreditam que as cotas, na sua modalidade social, são um recurso válido no combate as desigualdades educacionais no Brasil, sobretudo, no acesso ao ensino superior. No entanto, eles não acreditam que esta seja a única medida que possa combater as desigualdades educacionais, e que o melhoramento da escola pública deve ser encarado como prioridade pelo Estado. Alguns alunos consideram as cotas uma medida paliativa, e dependendo de como aplicada, pouco eficaz.

A eficácia das cotas nos cursos que pesquisei foi por muito tempo um dos argumentos utilizados pelos grupos contrários, estes grupos argumentavam como seria possível um aluno sem a formação básica completa, acompanhar os cursos de Direito e Medicina, por exemplo. Como assistir as aulas de Bioquímica ou de Teoria Geral do Estado, se esses alunos mesmo antes de ingressar já eram considerados inaptos, por considerarem que a qualidade de sua formação básica era deficiente em matérias como: Química e História, por exemplo.

As justificativas que os alunos cotistas fazem sobre as ações afirmativas divergem em muitos pontos das afirmações que seus colegas não cotistas fazem sobre as cotas. Para os alunos cotistas, o sistema de reserva de vagas oportunizou prioritariamente possibilidades de ascensão social e econômica,

3M: (...) Ter uma condição de exercer uma profissão que o retorno financeiro é bacana. Eu nunca teria o retorno financeiro que eu vou ter, se eu não estivesse entrado na universidade... É... A perspectiva é boa, principalmente financeira, e é uma coisa que eu gosto. Mas, falando em termos financeiros, se você for pensar hoje no Brasil, no caso médico generalista, se ele for pro Mais Médicos ele tem um salário de dez mil reais! Tipo... Sem especialização nenhuma! E tipo, fora 
do meu curso... Sei lá... Sem isso... Se eu tirasse isso da minha vida, eu não me veria em lugar nenhum ganhando dez mil reais. Eu acho que a perspectiva financeira é bacana, e tipo meio que social, porque é igual... Eu nunca teria o respeito e o reconhecimento da sociedade que eu terei, que eu vou ter em função do curso, em função das cotas também, porque se não fosse as cotas eu não tinha entrado.

Assim como para outros alunos cotistas, as expectativas sociais e financeiras acarretadas pelas cotas geram um efeito tão real, que para muitos deles esse argumento basta para justificar a aplicação da reserva de vagas. Para eles, que são usuários da política, a consequência do programa está atrelada a uma perspectiva pessoal de crescimento social, independendo os argumentos sobre promoção de justiça e igualdade. 0 que não quer dizer, que esses alunos não tenham nada a dizer, muito pelo contrário.

A forma como eles encaram as cotas passa tanto por uma percepção pessoal de suas trajetórias, quanto por sentidos de justiça e combate as desigualdades que eles acreditam ter este tipo de política no plano geral. Os alunos cotistas elencam em quais pontos, para eles, a política de cotas desempenha seu papel de recurso público que promove justiça social.

A “justiça” das cotas, para os alunos cotistas é entendida na perspectiva de oportunizar uma chance de ingresso para as pessoas que não podem e não tem como competir por uma vaga disputada pela ampla concorrência, como nos cursos de Medicina e Direito. 0 mérito das cotas para esses estudantes é reconhecer a injustiça numa competição entre alunos bem preparados e alunos medianamente ou mal preparados,

6D: Eu estudei em escola pública a vida toda, meu ensino médio não foi em uma escola tão ruim... eu estudei no CEFET, só que em Lagarto.Os professores são os mesmo, o pessoal e eu fiquei no primeiro ano, por exemplo, só um exem- 
plo, eu fiquei sem professor de inglês até outubro! Aí você imagine, eu vou disputar com alguém que tem toda uma estrutura? Eu não ia, não conseguiria mesmo! Eu fiz doze mil e alguma coisa, e o último que passou, o último da classe "A" passou com treze mil duzentos e vinte e cinco, foram mil e alguma coisa de diferença entre eu e o último da classe "A".

Para os alunos cotistas, as vagas dos cursos mais disputados tendiam a ficar para os alunos mais preparados que seriam aqueles com maior poder aquisitivo. Segundo os estudantes cotistas, o sistema de reserva de vagas consegue de alguma forma romper com essa manutenção de perfis sócio econômicos no ingresso, especialmente, nos cursos mais prestigiados. Os alunos admitem que assim, as relações educacionais tanto fora da universidade quanto internamente se alteram, pois, o privilégio de estudar Direito ou Medicina passa a ser de mais pessoas. Para alguns dos estudantes cotistas, a forma como o vestibular sempre existiu, consistia como instrumento de fomento das desigualdades sociais e que o reflexo disto seriam os candidatos aprovados ao final de cada vestibular.

Para os estudantes cotistas, a promoção da justiça social e o combate às desigualdades acontecem quando, pela primeira vez é oportunizada a um estudante pobre e negro a possibilidade de concorrer a uma vaga em um curso disputado. Ressalto, que os alunos cotistas dos cursos de Direito e Medicina admitem que o acesso à universidade seja uma realidade para alunos da rede pública, desde que estes alunos optassem por cursos de baixa concorrência e de profissões menos prestigiadas. 0 que eles festejam e enxergam como justo, é a possibilidade de ingresso em cursos nos quais eles dificilmente ingressariam. 0 sistema de cotas para eles é a concretização de que é possível ser aluno do curso de Medicina e Direito de uma universidade pública. Para eles, isso é justiça.

No entanto, para os alunos cotistas, o sistema de reserva de vagas ainda não conseguiu atingir efetivamente a camada de alunos negros da escola pública. Eles não conseguem visuali- 
zar ainda muitos colegas negros cotistas ou em uma proporção parecida com o número de colegas oriundos da escola pública. Como afirmam Silva e Pacheco, "cabe destacar que o sistema de cotas se mostrou mais efetivo para estudantes da escola pública, inclusive pelo fato de que as vagas não utilizadas na cota de negros foram somadas àquelas destinadas à escola pública." (SILVA e PACHECO, 2013, p. 71/72).

Um dos argumentos mobilizados por os alunos cotistas e não cotistas são as justificativas históricas e sociais vividas por uma parcela da população brasileira. Alguns alunos de ambos os grupos, como também professores acionaram a formação histórico e econômico que o Brasil viveu e vive para justificar a adoção de medidas de reparação social, tais como o sistema de reserva de vagas. Alguns alunos não cotistas confessam que precisaram fazer uma reflexão histórica e social para poder entender a adoção da política de cotas,

Eu: As cotas são uma medida justa?

4M: Sim, considero. Engraçado... A evolução do meu pensamento, vou tentar explicar. Tipo, eu sempre estudei em escola particular e tudo. Nunca tive contato com essa coisa. Escola pública? Nunca tive contato! Tinha uma amiga que estudava no CEFET, que era a favor das cotas e que às vezes eu conversava com ela, mas mermo [sic] assim não mudava de ideia. Enfim, porque nunca tive um momento de me aprofundar sobre o assunto, porque é um assunto que ou você vivencia a realidade para entender mesmo, ou você acabar tendendo a ser contra... Aí pronto! Aí eu tinha essa visão contra, teve a passeata contra cotas, eu tava [sic] lá na passeata contra cotas. Segundo ano de ensino médio, 16 anos de idade. Eu fui inclusive várias pessoas que tão hoje no centro acadêmico comigo tavam [sic] nesse momento, entendeu? A gente até brinca hoje... Meu Deus do céu, que absurdo!

Para alguns estudantes não cotistas, ser contrário a medidas como a política de ações afirmativas é uma postura descabida na 
atualidade, mesmo que eles tenham sido contra as cotas em outro momento da vida. Tais afirmações apontam uma flexibilização das posturas e das concepções que eles faziam e fazem sobre justiça e igualdade, por exemplo. Todavia, existem alguns alunos não cotistas que continuam entendendo a política de cotas como uma medida que não se justifica, alunos que continuam contra qualquer tipo de politica de cotas.

No entanto, no levantamento que realizei, a maioria dos estudantes entende a política de cotas como um recurso positivo e que auxilia no combate as desigualdades sociais, eles acreditam nas cotas sociais como um instrumento positivo. Os aspectos da renda e da origem escolar, para esses alunos é que devem ser considerados como condicionantes para aplicação do sistema de cotas. Por isso, as cotas sociais são aceitas por boa parte dos estudantes, mesmo havendo ainda posicionamentos contrários a qualquer sistema de cotas.

Para os alunos, as cotas sociais carregam os sentidos de igualdade e justiça e não comprometem os sentidos da meritocracia. As cotas sociais são admitidas como medidas que oportunizam o ingresso de pessoas que não teriam outro tipo de chance de ingresso na universidade,

9D: (...) Pessoas que de repente tem uma renda inferior, a gente sabe que não tem acesso a melhores escolas. Então, igualar as oportunidades de acesso à universidade entre as pessoas que tem acesso as melhores escolas particulares e as pessoas que não tem é no mínimo justo.

Um fato notado apenas por alunos não cotistas e considerado como uma falha no sucesso das ações afirmativas é a dimensão do sistema. Alguns alunos acreditam que como os critérios utilizados pelas cotas são da origem escolar e a autodeclaração, muitos dos alunos aprovados seriam de pessoas com faixa etária avançada e trabalhadores. Os alunos consideram que esse perfil de aluno não deveria ser contemplado com a política de cotas, 
pois, sendo trabalhadores eles podem pagar cursinho preparatório como também um curso numa universidade particular. Para esses alunos, algumas das vagas estariam sendo destinadas para usuários com perfis que não atendem plenamente o objetivo que eles julgam como "correto".

A escola pública também é citada como responsável pelo fracasso no ingresso dos alunos das camadas populares. Neste ponto, as opiniões dos alunos cotistas e não cotistas são dirigidas numa mesma perspectiva de considerar a escola pública um instituto do Estado que não responde plenamente as funções que lhe foram destinadas. Ambos os grupos avaliam o sistema de ensino público como ineficiente para preparação nas disputas de vagas em um vestibular, como também de propiciar uma estrutura adequada dos conteúdos básicos de ensino que por vezes são exigidos no ingresso ao ensino superior.

Esse ambiente escolar criticado por ambos os grupos de alunos, também é julgado como insatisfatório nos estímulos que oferecem para os seus alunos, especialmente, para aqueles que desejam ingressar na universidade. Sendo este também, um dos motivos que justificam a implantação das cotas sociais.

Tornou-se consenso que a competição entre alunos oriundos da escola pública e da escola privada não é equânime. Os grupos de alunos com quem tive contato reconhecem em seus argumentos as dificuldades que cercam a vida de aluno oriundo da rede pública de ensino. Os quesitos ligados à escola pública, rede privada versus pública, desigualdade e exclusão social são acionados e eleitos como válidos e relevantes para justificar a adoção de reserva de vagas. Mais do que isso, hoje, as cotas são consideradas por eles como medidas necessárias diante deste panorama.

Não obstante, os alunos julgarem as cotas como um recurso necessário, eles também entendem a medida como uma ação do Estado que não prioriza o que de fato, para eles, deveria ser pre- 
eminente: a educação pública. Neste sentido, os alunos criticam a atuação do Estado com ensino básico e a forma desprivilegiada que o Estado trata, notei que em nenhum momento os alunos avaliam também os seus cursos enquanto parte integrante da educação pública. Os alunos não questionam a quantidade de vagas ofertadas nem o modelo de educação superior. 0 sentido de meritocracia ainda é prioritário para eles, na perspectiva que o Estado deveria, com a educação pública, preparar melhor os seus alunos para disputa de vagas.

Os alunos também não questionam o formato de seleção para ingresso no ensino superior, por mais que concebam o vestibular como uma prova de "decorar". Existe um consenso em entender a necessidade de algum tipo de seleção para o ingresso das pessoas no ensino superior, especialmente, no público. Nos cursos em questão, os alunos valoram ainda mais a prova de seleção, pois, eles consideram as suas áreas profissionais como essenciais no funcionamento da sociedade, e por isso não se pode capacitar "qualquer" pessoa para ser advogado ou médico.

Para alguns alunos, o que compromete o mérito das cotas é a possibilidade do ingresso de "qualquer um" em um curso como de Medicina e Direito. Os alunos deslocam o sentido da meritocracia, como algo destinado aos que alcançaram o mérito, para uma perspectiva de status social. Estou querendo dizer que para alguns alunos, as pessoas que devem e podem ingressar no curso de Direito e Medicina são aquelas que não só estão melhores preparadas intelectualmente, mas socialmente também. Com isto, pode se supor porque as relações entre os alunos cotistas e não cotistas não são facilitadas.

Os entendimentos sobre a justiça das políticas públicas de ingresso na universidade caminham na perspectiva de que as cotas sociais são a medida mais justa e necessária para a promoção das camadas populares à universidade. No entanto, esses alunos visualizam a medida como um recurso limitado, que para os alu- 
nos cotistas seria restrito, em alcance. Para eles a universidade com as cotas deveria receber ainda mais alunos das camadas populares. Para os alunos não cotistas a medida é limitada quando o Estado não prioriza a qualidade da educação básica, e principalmente, quando possibilita o ingresso de "qualquer pessoa" ao ensino superior. Os alunos não cotistas mesmo avaliando as cotas como justas e necessárias, resistem em compartilhar o espaço acadêmico com as camadas populares. Revelando assim, como eles ainda concebem o espaço universitário como um privilégio das camadas sociais as quais pertencem.

Ou seja, os alunos cotistas criaram uma estratégia enunciativa, em que eles promovem as cotas sociais e ao mesmo tempo deslegitimam a política, assim como alguns setores da opinião pública vinham fazendo. Ainda assim, considero que os estudantes não cotistas ao fazerem isso, elaboraram um modo peculiar conceber seus critérios de justiça para o sistema de reserva de vagas. Isto é, para esses estudantes, as cotas são positivas no combate as desigualdades no acesso, mas são negativas com relação ao mérito de quem as acessa.

Outros critérios de justiça são utilizados pelos alunos cotistas, no caso deles, as cotas também seriam positivas no combate as desigualdades, mas negativas no alcance. Ambos os grupos criaram formas de entender a justiça das cotas, concordando, sobretudo, no combate as desigualdades que o sistema promove. Sendo esta, a justificativa que mais influência para aceitação do programa de ações afirmativas em ambos os grupos. Afinal, todos são contra as desigualdades sociais.

Em geral, os estudantes acham justas as cotas, pois consideram injustas as desigualdades, fato consensual entre cotistas e não cotistas. Por outro lado, consideram injustas quando os atinge diretamente, no caso dos alunos não cotistas com a diminuição das vagas de disputa e compartilhamento do espaço universitário com esses estudantes da rede pública e negros. Para os co- 
tistas, a injustiça continua a acontecer quando eles percebem a desigualdade no meio universitário e reivindicam mais alunos das camadas populares e mais negros na universidade.

Esses grupos que estão vivenciando as cotas começam a questionar os condicionantes de justiça que balizam o programa a partir das suas próprias experiências e das experiências dos seus colegas. Esses alunos introduzem não só suas perspectivas sobre a justiça das cotas, mas questionam a validade da medida na prática. Eles começaram a avaliar os efeitos das cotas a partir de uma perspectiva interna e cotidiana.

Objetivamente quis responder quais eram os sentidos de justiça e quais critérios foram incorporados ao repertório das justificações sobre o caráter de justiça social que as cotas podem ter enquanto medida pública. Notei que em alguns pontos, alunos cotistas e não cotistas convergem nas opiniões sobre o aspecto positivo promovido pelas cotas, neste caso, o combate às desigualdades sociais.

Estudantes cotistas e não cotistas também acionam as suas percepções de justiça e injustiça a partir das suas experiências pessoais com as cotas. Por exemplo, para alguns alunos não cotistas, a justiça das cotas já existe quando dá possibilidade deles ingressarem nos cursos que ingressaram. Para os alunos não cotistas, a injustiça das cotas acontece quando eles precisam ser preparar mais para disputar uma vaga nas graduações de Medicina e Direito. Essas experiências atingem diretamente os sentidos que a justiça social das cotas promove.

Todos esses pontos giram em torno de como esses grupos formularam estratégias para justificar suas opiniões sobre as cotas sociais. Pois, mesmo com as críticas e os elementos que eles consideram injustos na política de cotas, há um consenso na necessidade de implantação do sistema de reserva de vagas na sua modalidade social. 
Por meio desse tipo de argumento é que foram construídas as considerações que justificam e garantem a sustentação das cotas sociais de uma forma geral. No entanto, no contexto das ações afirmativas e da política de cotas, o fator "raça" não foi mobilizado pelos estudantes como um condicionante que justifique a adesão das políticas de cotas. Os alunos de ambos os grupos não acionaram o combate às desigualdades raciais como um elemento que justificasse as cotas; a raça, o racismo e o preconceito racial não são levados em consideração no debate sobre a justiça social promovida pelas as ações afirmativas no caso dos cursos pesquisados.

\section{Justiça Racial ou Como não se debate raça na comuni- dade acadêmica}

Diferente do que ouvi sobre as cotas sociais e a aceitação que as mesmas ganharam junto às pessoas, em especial, sustentadas pelos argumentos da justiça, do combate à desigualdade e do descrédito na escola pública, os entendimentos sobre as cotas raciais não caminharam nessa mesma perspectiva. Em alguns momentos, o argumento do fato histórico da escravidão e às suas sequelas sociais e matérias são acionados, porém, não no sentido de promover a implantação das cotas na sua modalidade racial.

A compreensão que se faz é que as cotas sociais conseguem promover a inserção das camadas populares na universidade e, com isso, trariam também os grupos de não brancos, pois não há controvérsias entre estes alunos sobre o fato de que a maioria pobre no Brasil é negra. A resistência em aceitar ou mesmo pensar a legitimidade da implantação de cotas raciais, passa também pelo de fato de que não se debate raça nem relações raciais no sistema escolar das trajetórias destes alunos.

Nos cursos em questão, a evidente exclusão do tema é facilmente notada, seja pelo formato político pedagógico do curso, seja 
pelo histórico do curso que não privilegia esse tipo de discussão. Esse também é um imperativo que ocasiona o distanciamento sobre a discussão com relação ao racismo no Brasil. Os mitos da democracia racial e de ausência de racismo no País tornam este tema invisível no debate público interno e externo à universidade. Concordo com Silvério, quando ele aponta um dos motivos que fazem com que não se discuta o tema,

\begin{abstract}
No Brasil, no entanto, existiu e existe uma tentativa de negar a importância da raça como fator gerador de desigualdades sociais por uma parcela significativa dos setores dominantes. Só muito recentemente vozes dissonantes têm chamado a atenção sobre a singularidade de nossas relações raciais. (SILVÉRIO, 2002, p.223)
\end{abstract}

Pelo fato de não ser considerado um "fator gerador de desigualdades sociais" a raça não é considerada como um condicionante válido à aplicação de reserva de vagas no acesso ao ensino superior, por parte destes alunos. As desigualdades sociais se consolidaram como justificativas razoáveis para que determinada políticas públicas fossem implantados. Neste caso, as ações afirmativas no sua modalidade de cotas sociais são justificadas e justas para eles, pois as desigualdades sociais estão incorporadas ao repertório de categorias válidas. Em oposição a isso, a categoria "raça" é questionada enquanto instituto eficiente na compreensão das desigualdades.

Convencionalmente, tende-se a compreender a raça como um elemento não legítimo na busca das justificativas sobre as desigualdades entre as pessoas. Desta forma, é possível compreender por que as cotas raciais não são legitimadas no âmbito de um mecanismo que promova a redução da desigualdade no Brasil. Seguindo uma tendência nacional, os alunos preferem entender que o condicionante da raça não é um imperativo válido. Percebi também que há um constrangimento em falar de raça, um receio em revisitar o seu conceito. 
Pereira (2007) alerta que os discursos associados ao debate sobre as cotas raciais são permeados de outros sentidos, geralmente acionados pelos interlocutores na perspectiva de apontar quais seriam os quesitos verdadeiramente importantes numa discussão sobre as desigualdades e as formas de combatê-las. Destes argumentos, alguns são mais evidenciados em detrimento de outros. Nesta pesquisa, notei que os argumentos sobre a exclusão social, escola pública e papel do Estado foram evidenciados a todo o tempo. Em contrapartida, nenhum dos entrevistados falou sobre racismo, preconceito racial, desigualdade racial e discriminação como elementos que fazem parte dos processos de desigualdades e injustiças sociais.

Entendo que as formulações enunciativas dos sujeitos universitários estão inscritas num formato em que se nega a existência de racismo e de discriminação racial. As negações do racismo e do preconceito racial, feita pelos meus entrevistados, como parte das compreensões que eles fazem sobre os tipos de condição social que os grupos negros no Brasil desfrutam. Por mais que eles reconheçam os problemas gerados pela escravidão, eles não acreditam que este fato exerça influência na vida das pessoas negras de hoje, eles negam que exista um estigma social causado por um fator racial e histórico.

O empenho argumentativo dos alunos é responsabilizar o fracasso da escola pública como condicionante no acesso das camadas populares à universidade e outro aspecto seria a desigualdade de renda,

A defesa da escola pública e a responsabilização do poder estatal, a alusão à miscigenação, a referência ao mérito acadêmico e à desigualdade/exclusão social, todos esses discursos parecem constituir uma recusa explícita ao debate sobre a base da questão: o racismo brasileiro. (PEREIRA, 2007, p.292)

Além desse fato, o leque de argumentos que invalidam as cotas raciais também se vale da prerrogativa de que não se sabe quem 
é negro no Brasil. Na estrutura da entrevista semiestruturada não constava uma pergunta direta sobre as cotas raciais, geralmente eu introduzia uma pergunta sobre as cotas raciais depois que os entrevistados me forneciam suas opiniões sobre as cotas em geral e sobre as cotas sociais.

Boa parte dos alunos de ambos os grupos e dos professores confessaram uma dificuldade em emitir uma opinião sobre as cotas na sua modalidade racial. Essa mesma dificuldade aconteceu quando os interroguei sobre o que entendiam por raça. Outro dado que demonstra o distanciamento da discussão é o fato de que nenhum dos entrevistados entre alunos e professores utilizou o termo "afro-descendente". Compreendi que esse reduzido conjunto de termos utilizados por eles para abordar a discussão sobre as relações raciais denota distanciamento sobre o tema.

Nenhuma das opiniões emitidas pelos grupos de alunos não cotistas e por alguns cotistas ou pelos professores deu sentido prático ao efeito real do racismo e da discriminação racial como condicionante nas disparidades de acesso ao ensino superior. Isto é, as opiniões caminharam na perspectiva de deslegitimar a implantação das cotas na sua modalidade racial. De questionamentos que iam desde saber quem é negro no Brasil ao de comparar a condição de privilégios entre brancos pobres e negros, ambos os grupos demonstram que não entendem que haja justiça social na promoção das cotas raciais,

Professor B: Sobre as cotas me ocorreu agora que... Por exemplo, talvez seja até reiterativo isso, por exemplo, eu tenho conhecimento, você, as pessoas tem conhecimento, né? De pessoas brancas e pobres que não tem acesso. Por exemplo, eu conheço várias pessoas pobres brancas, mais brancas do que eu, digamos assim, num é? Mais brancas do que eu e que não podem, jamais vão tá [sic] aqui numa universidade. Como é que fica esse pessoal? Aquilo que... É uma questão determinada... Que embasa aquela minha tese ini- 
cial de ser contra essas cotas. Porque eu, por exemplo, eu tenho vários conhecidos meus pobres brancos, mais brancos do que eu! Vou repetir, do olho azul como se diz a história, né? 0 que não é o meu caso, e que o sujeito jamais vai ter acesso à universidade. Já os negros, os mulatos, os pardos tem essa prioridade. Então, eu... É... É... Uma coisa que me incomoda isso ai, como vai resolver essa questão? Essa outra parcela da população que é branca, tem olho azul, olho verde tem isso e aquilo, mas é pobre e não tem acesso. Como é que fica? Pronto. Você me lembrou bem, até... Interessante você puxar agora esse assunto, eu sou mais, digamos assim, simpático a tese, como é nome, a tese da pobreza.

Eu: Cota social?

Professor B: A cota social. Eu, sinceramente concordo muito mais com a cota social do que com a cota da cor da pele, da, da, da cota racial, num é isso?

Eu: É, cota racial. Aqui na UFS há adoção das duas.

Professor B: Mas eu acho que seria, se eu fosse o reitor entre aspas, eu ia colocar cota social, porque a cota social é mais justa. [pausa] Sociologicamente eu sou mais razoável, como Demétrio. Que é um, um, um doutrinador, um jornalista, um critico é... Eu sou favorável à tese das cotas sociais. Eu penso.

Há um desconforto em falar sobre a politica de cotas raciais, elas não são consideradas medidas legítimas da atuação no combate às desigualdades. Este professor, na tentativa de maximizar as marcas raciais que fazem parte do debate sobre ações afirmativas questiona como ficariam os indivíduos brancos dos olhos "azuis ou verdes". A intenção dele foi rivalizar com as marcas raciais que fazem parte dos aspectos de identificação racial que as cotas raciais visam atingir, querendo demonstrar que na esfera das necessidades o fator da raça não deve ser levado em consideração.

A resistência em trazer a inserção da politica de ações afirmativas na modalidade cotas raciais para arena de justificações positivas passa pelo entendimento dos entrevistados como se o fator 
sócio econômico fosse satisfatório na referência para implantação de medidas públicas.

Encarar as cotas raciais desta forma parece ser uma decorrência de como os debates vem acontecendo no ambiente acadêmico destes cursos ou como eles não veem acontecendo. 0 que distancia a reflexão sobre os aspectos positivos da política afirmativa sobre a inserção dos negros no ensino superior, desde seus efeitos quantitativos aos aspectos qualitativos. Segato (2005) alerta para outras possibilidades de efeitos contrários aos esperados, por exemplo, pelos Movimentos Sociais Negros,

\begin{abstract}
(...) o segundo - e que faria da experiência um fracasso - é que sua finalidade seja reduzida à formação de uma aristocracia negra ao contribuir na instalação de um novo grupo de poder em lugar de formar uma massa crítica capaz de introduzir modificações substantivas nas formas e nos objetivos da produção de conhecimento e no exercício do poder porque traz consigo experiências comunitárias de outro tipo. (SEGATO, 2005, p. 14)
\end{abstract}

Penso que nos cursos que tive contato, a redução à formação de uma elite técnica em suas respectivas áreas carrega chances de reais de efetivação. Os cotistas raciais destes cursos não foram contagiados pelo discurso de base dos Movimentos Sociais Negros com relação à identificação racial ou à ocupação dos espaços de poder pelos grupos negros. Este também pode ser o reflexo do debate sobre o assunto numa perspectiva mais regional, no caso do estado de Sergipe, que reverbera no contexto da universidade. Cabe refletir mais e melhor sobre quem é considerado negro em Sergipe e como eles estão acessando a universidade, seja através das cotas raciais ou não.

A perspectiva sobre como a raça não deve ser utilizada como critério legítimo na promoção da justiça social acompanha as opiniões dos alunos também. Em sua maioria, eles não conseguem associar que 
as cotas raciais seriam um tipo de recurso que ajudaria no combate aos níveis desiguais de acesso ao ensino superior. Os alunos acreditam que a cor da pele não deve ser um componente relevante na aplicação de medidas reparatórias. De formas diferentes, eles refutam a ideia da cota racial como não tão justa quanto à cota social,

6M: (...) Eu acho que, num sei, na minha visão que as cotas raciais elas carregam um preconceito muito grande, que eu acho que a raça, a cor da pele não. Eu não vejo que isso possa ser um critério diferenciador do intelecto de uma pessoa. Talvez essa pessoa, ela pode carregar consigo uma marcar de preconceito histórico, a questão escravidão, isso é fato. Infelizmente a gente tem isso hoje. Mas eu não acredito... Há pelo fato de a pessoa ser negra ela vai ser menos inteligente do que uma pessoa que é branco, por exemplo. Eu acredito que a capacidade é a mesma.

Mesmo reconhecendo os fatos ligados a escravidão no Brasil, os alunos não compreendem como este evento tenha reflexo nos dias atuais. Para eles, uma pessoa pobre carrega as marcas necessárias para ser usuária de uma política tal qual a política de cotas, em contrapartida uma pessoa negra não é igualmente avaliada como um usuário de uma medida como as cotas por conta exclusivamente do seu fenótipo ou cor de pele. Por mais que os alunos se atentem para os processos históricos ligados a população negra no Brasil, estes não se tornam os argumentos principais em suas opiniões. Refletindo assim, em qual grau de importância das justificações se encontra o critério da raça como gerador de desigualdades,

Eu: Você é a favor da cota racial?

7D: Então... [pausa] Em relação à universidade? Então, eu ainda não cheguei meio que num consenso sobre isso. E ate tava [sic] uma polemica sobre cotas em concurso público. Eu, eu não sei. Porque eu tava [sic] até falando com 3D, porque parece que dentro do próprio Movimento Negro tem uma divergência, 
né? E eu não sou muito conhecedora e no auge da minha ignorância. Assim, eu penso que se você fosse explorar esse viés socioeconômico e desse oportunidade para pessoas que estão na base da pirâmide de exploração para que elas chegassem, chegar mais. Você acabaria abordando o, a, a parcela negra da sociedade, porque historicamente a parcela explorada, que historicamente ta [sic] na base. Mas também tem aquele argumento que a, a mesmo que não teja [sic] lá um histórico de opressão e tal. Eu, eu ainda prefiro o viés mais socioeconômico mesmo, porque eu acho que acaba abordando.

Eles entendem que se houver combate as desigualdades sociais a partir do critério econômico, a população negra seria atingida, não necessitando assim, a aplicação de cotas raciais. Além disso, a divergência de quem seria negro no Brasil faz com que muitas opiniões sobre as cotas sejam questionadas na forma de utilização feita pelas pessoas. Neste caso, este argumento aparece quando a aluna cita o que haveria algum tipo de divergência sobre o tema no Movimento Negro. Alguns alunos também acreditam que o fomento das cotas raciais seria mais uma forma de discriminação e preconceito, criando assim, um efeito contrário ao previsto.

Essas opiniões foram emitidas por alunos não cotistas e alguns cotistas, quando feitas pelos alunos cotistas, eles demonstravam também porque não acreditavam no efeito prático das cotas a partir das experiências que estavam vivendo na universidade e nos seus cursos. A representatividade das camadas de alunos negros, cotistas raciais, é questionada pelos próprios estudantes cotistas, que afirmam não percebe o ingresso de tantos colegas negros. Para eles, o acesso de alunos afrodescendentes nos cursos de Medicina e Direito é limitado e não atinge aquele "aluno negro de periferia". Em alguns casos, eles acreditam que os alunos negros que conseguiram ingressar nas respectivas graduações são aqueles que reúnem recursos para pagar um cursinho preparatório. Segundo eles, quando isso acontece o sentido das cotas raciais passa a ser questionado, pois, esse tipo de aluno negro que ingressa não é considerado por este grupo como aquele usuário "ideal" da política de cotas. 
No entanto, a inserção de alunos negros nestes cursos mesmo de forma frágil foi notada tanto pelos alunos e pelos professores. Esse efeito aconteceu tanto na perspectiva do questionamento dos alunos que revelam a convivência com colegas negros, como por parte dos professores que admitem uma maior diversidade racial em sala. Ainda assim, os cotistas raciais são aqueles, dentro dos grupos de alunos cotistas, que mais optaram pela invisibilidade, eles são os alunos cotistas em que há maior dificuldade no acesso e diálogo. Em geral, eles não se identificam como cotistas raciais, restringindo sua identidade de acesso ao fato de serem usuários das políticas de cotas.

Entendi que os cotistas raciais querem evitar situações onde sejam questionados sobre a sua condição racial, ou que tipo de estigma carrega pelo fato de se considerarem negros. Optar pela invisibilidade, faz com que eles não sejam protagonistas de situações desconfortáveis ligadas aos aspectos da validade do sistema das cotas raciais, ou mesmo de serem interrogados sobre o quão são negros para acessar o sistema de cotas na modalidade racial.

Acredito que isso também aconteça, por conta do distanciamento que os Movimentos Sociais Negros tenham neste momento das ações afirmativas no espaço universitário. Não consegui detectar um ambiente favorável para que alunos e alunas cotistas raciais se identifiquem e externalizem essa condição. 0 NEAB, da Universidade Federal de Sergipe, também não tem atuado nesta perspectiva. Todavia, após a adoção das cotas, visualmente professores e alunos admitem que a universidade tenha passado a contar com mais estudantes não brancos. Essa afirmativa também remete ao fato de que anteriormente as cotas, a universidade se caracterizava pelo ingresso de pessoas brancas, sobretudo, nos cursos em que realizei a pesquisa,

Professor B: Como disse Tomas Bastos, criminalista, talvez o maior criminalista do país, as universidades morenizaram. 
A partir dos relatos colhidos, consegui perceber que o debate sobre raça e as relações raciais no Brasil são invisibilizados nos cursos de Medicina e de Direito. Com isso, prevalece o desprestigio do valor das cotas raciais como promotoras da justiça social. É possível notar que a prerrogativa de se falar de raça ou de distinção racial, eleita pelos grupos que abordei, parte da expectativa de questionar a validade da modalidade deste tipo de cota. Desta forma, eles preferem mobilizar argumentos que legitimam as cotas sociais em oposição às cotas raciais, acionando o valor de injustiça social como reflexo das desigualdades econômicas.

Entendi que a dificuldade em se debater raça ou as estratégias para tornar o debate sobre o assunto invisível, marcam a profunda distância que a reflexão do tema tem junto ao contexto universitário, em especial, nos referidos cursos. Essa distância parte também do espaço invalidado da prerrogativa da raça enquanto condicionante da desigualdade no Brasil e no estado de Sergipe.

0 argumento frequente da desigualdade econômica, para os grupos de alunos e professores garante que a raça não deve ser encarada como um fator justo na adoção de política de cotas. Usando toda forma de argumento em que a desigualdade econômica é entendida como protagonista dos problemas sociais, educacionais, econômicos e culturais no Brasil. Esses grupos ignoram as perspectivas relacionadas às relações raciais no que tange entender este aspecto como protagonista também dos problemas sociais, econômicos, educacionais e culturais.

A esfera acadêmica continua a rejeitar a categoria raça como um imperativo marcado por fortes fatores, que alavancaram o insucesso de uma camada da população brasileira. 0 desconforto e 0 incomodo são sinais evidenciados nas falas e formas de posicionar quando se precisar falar de raça. Neste momento, é possível perceber como, a ideia fixa do protagonismo da desigualdade social nos problemas nacionais, e como a discussão sobre raça, para eles, não infere em construções e significados socialmente relevantes. 
Diante deste panorama de sentidos empregados à raça e às cotas raciais, também é possível entender o porquê os cotistas raciais da UFS optam pela invisibilidade. Afinal, os cotistas ingressantes pelo critério das cotas raciais lidam tem que lidar com a compreensão geral de que a sua forma de acesso não é tão justa quanto à das cotas sociais. Este aspecto também é estimulado pelo distanciamento do debate e a isenção de responsabilidades sobre o assunto. Ou seja, os grupos acadêmicos de Medicina e Direito não discutem raça, discriminação racial, racismo e desigualdade racial.

\section{Considerações finais}

Neste artigo, problematizei a experiência cotidiana dos alunos cotistas e não cotistas nos cursos de Direito e Medicina, assim como investiguei quais percepções de justiça social, igualdade, meritocracia estão sendo produzidas por esses estudantes. Notei que esses alunos cotistas e não cotistas começam a avaliar os efeitos da política de cotas a partir de uma perspectiva interna e cotidiana.

As enunciações dos alunos me fizeram concluir que há um cotidiano acadêmico nitidamente demarcado por aspectos utilizados pelos alunos para se distinguir entre si, especialmente os alunos não cotistas dos alunos cotistas. Sendo os espaços de integração escolhidos como instrumentos para inclusão ou exclusão dos colegas de turma. Percebi assim, que as formas de segregação dos grupos acontecem de forma sutil e numa medida onde é difícil questionar se os alunos estão discriminando ou sendo discriminados.

Conclui também que ainda existem muitas dificuldades para as pessoas negras e pobres em Sergipe, e isso é ainda mais difícil em espaços que jamais foram pensados para esses grupos. Isto é, ser cotista na modalidade cota racial nos cursos de Direito e Medicina é uma tarefa desgastante. Principalmente, porque o 
imperativo da "raça" não é concebido como um instrumento que provoca desigualdades sociais, isto é, para maioria desses alunos a desigualdade no seu caráter racial não é protagonista dos problemas sociais.

Em contrapartida, os alunos concebem as cotas sociais como medida necessária e mesmo justas em certo grau. Levando em consideração o fracasso da escola pública e os aspectos ligados a renda, a maioria dos alunos cotistas e não cotistas amparam suas justificações sobre a validade da implantação da política de cotas na sua modalidade social. Esses alunos entendem que desta forma o Estado e mesmo a sociedade, estariam sendo mobilizadas na luta contra as desigualdades sociais. Isto é, a justiça social das cotas na sua modalidade cota social está engendrada na perspectiva do combate as desigualdades sociais, sobretudo, no que tange as oportunidades educacionais.

\section{Ref erências Bibliográficas}

FRASER, Nancy. A justiça Social na Globalização: redistribuição, reconhecimento e participação. Tradução: Tereza Tavares. Revista Crítica de Ciências Sociais, n. 63. Out./2002.

GOFFMAN, Erving. Estigma: notas sobre a manipulação da identidade deteriorada. 2 Ed. Tradução: Márcia Bandeira de Melo Leite Nunes. Rio de Janeiro: Zahar Editores, 1978.

MUNIZ, Kassandra da Silva. A contribuição dos estudos de linguagem para o debate sobre as Ações Afirmativas para negros no Brasil. In: OLIVEIRA, Iolanda de ET al. Negro e Educação 4: linguagens, resistências e políticas públicas. São Paulo: Ação Educativa; ANPED. 2007.

; LIMA, Marcus Eugênio Oliveira. Percepções de justiça social e atitudes de estudantes pré-vestibulandos e universitários sobre as cotas para negros e pardos nas universidades públicas. In: MARCON, Frank Nilton; SUBRINHO, Josué Modesto dos Passos. Ações afirmativas e políticas inclusivas no ensino e público superior: a experiência da Universidade Federal de Sergipe. São Cristovão: Editora UFS, 2010. 
NEVES, Paulo S.C. A política de reserva de vagas da universidade federal de Sergipe para alunos de escolas públicas e não brancos: uma avaliação preliminar. In: SANTOS, Jocélio Teles dos (org.). 0 impacto das cotas nas universidades brasileiras (2004 - 2012) Salvador: CEAO, 2013.

PEREIRA, Larissa Santos. Mestiçagem, Racismo e Identidade: uma análise do discurso sobre cotas raciais enunciado por estudantes da universidade estadual de Santa Cruz. In: OLIVEIRA, Iolanda de et al. Negro e Educação 4: linguagens, resistências e políticas públicas. São Paulo: Ação Educativa; ANPED. 2007.

SEGATO, Rita. Raça é Signo. Brasília: Série Antropologia. n.372. 2005.

SILVA, Maria Nilza; PACHECO, Jairo Queiroz. As cotas na Universidade Estadual de Londrina: balanços e perspectivas. In: SANTOS, Jocélio Teles dos (org.). 0 impacto das cotas nas universidades brasileiras (2004 - 2012) Salvador: CEAO, 2013.

SILVEIRA, Paulo Roberto et al. Monitoramento, Permanência e Promoção da Diversidade: as ações afirmativas em risco na universidade federal de Santa Maria - RS. In: SANTOS, Jocélio Teles dos (org.). 0 impacto das cotas nas universidades brasileiras (2004 - 2012) Salvador: CEAO, 2013.

SILVÉRIO, Valter Roberto. Ação Afirmativa e o combate ao racismo institucional. Cadernos de Pesquisa, n. 117, p. 219-242. novembro/ 2002.

WALZER, Michael. Esferas da Justiça: uma defesa do pluralismo e da igualdade. Tradução: Jussara Simões. São Paulo: Martins Fontes. 2003.

Recebido em 20/10/2014

Aprovado em 03/11/2014 